LA W RENCE LIVERMORE NATIONAL LABORATORY

2011 Annual Health Physics

Report for the HEU transparency

Program

R. Radev

May 1, 2012 
This document was prepared as an account of work sponsored by an agency of the United States government. Neither the United States government nor Lawrence Livermore National Security, LLC, nor any of their employees makes any warranty, expressed or implied, or assumes any legal liability or responsibility for the accuracy, completeness, or usefulness of any information, apparatus, product, or process disclosed, or represents that its use would not infringe privately owned rights. Reference herein to any specific commercial product, process, or service by trade name, trademark, manufacturer, or otherwise does not necessarily constitute or imply its endorsement, recommendation, or favoring by the United States government or Lawrence Livermore National Security, LLC. The views and opinions of authors expressed herein do not necessarily state or reflect those of the United States government or Lawrence Livermore National Security, LLC, and shall not be used for advertising or product endorsement purposes.

This work performed under the auspices of the U.S. Department of Energy by Lawrence Livermore National Laboratory under Contract DE-AC52-07NA27344. 


\title{
2008 Annual Health Physics Report for the HEU Transparency Program
}

\author{
Radoslav Radev
}

Lawrence Livermore National Laboratory

This work is performed under the auspices of the U.S. Department of Energy by Lawrence Livermore National Laboratory under Contract DE-AC52-07NA27344 
Table of Contents

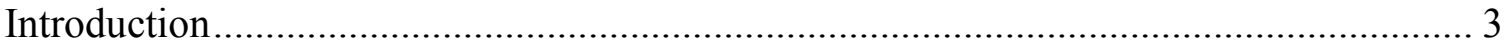

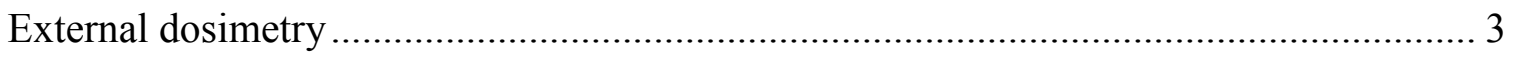

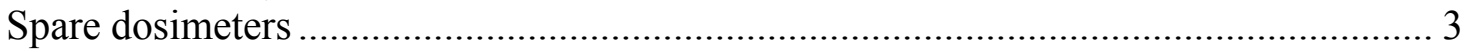

Dose information from the Russian dosimeters ....................................................... 3

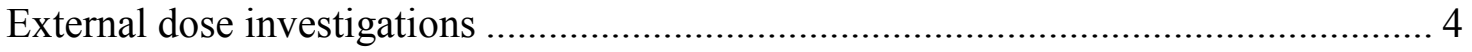

Logistics and reporting ................................................................................. 4

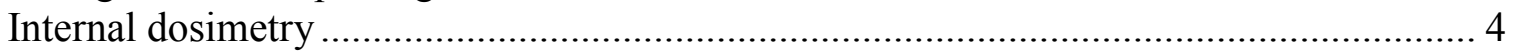

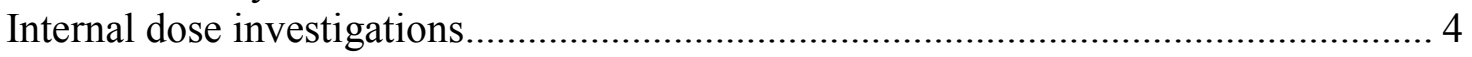

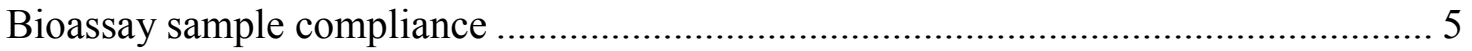

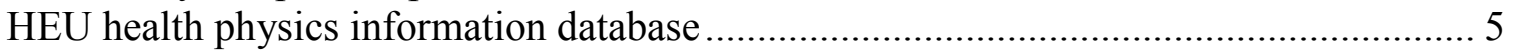

2008 Radiological data from the Russian plants....................................................... 5

Health physics support of the BDMS activities......................................................... 6

Neutron and gamma dose rate measurements for regulatory compliance and radiation safety reports for the BDMS source replacement ................................................... 6

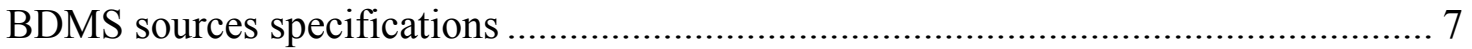

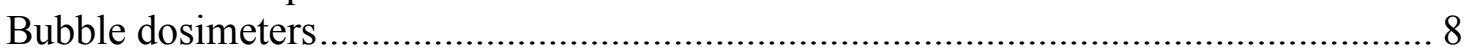

Information on HEU electronic information system (EIS) ...................................... 8

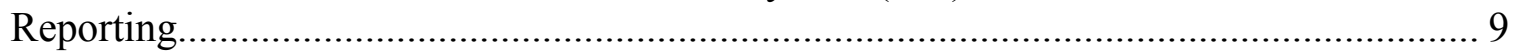

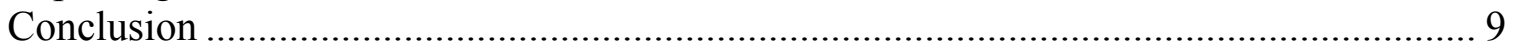

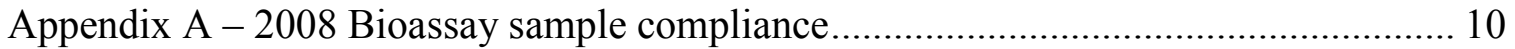

Appendix B - 2008 Russian plants radiological data charts ....................................... 11 


\section{Introduction}

During the 2008 calendar year, Lawrence Livermore National Laboratory (LLNL) provided health physics support for the Highly Enriched Uranium (HEU) Transparency Program for external and internal radiation protection. They also provided technical expertise related to BDMS radioactive sources and Russian radiation safety regulatory compliance. For the calendar year 2008, there were 158 person-trips that required dose monitoring of the U.S. monitors. Of the 158 person-trips, 148 person-trips were SMVs and 10 person-trips were Transparency Monitoring Office (TMO) trips. There were 6 monitoring visits by TMO monitors to facilities other than UEIE and 8 to UEIE itself. There were three monitoring visits (source changes) that were back-to-back with a total of 24 monitors. LLNL's Hazard Control Department laboratories provided the dosimetry services for the HEU Transparency monitors.

\section{External dosimetry}

LLNL provided 624 TLD dosimeters in 2008 for monitoring potential external dose: 304 personal dosimeters, 216 control dosimeters and 104 spares to Pragma and TMC in Moscow. Approximately 360 of the dosimeters supplied were returned and were not read. This number includes the unused spare dosimeters from Pragma and Moscow and both the personal and control arbitration TLDs left in Russia until a post trip dose letter is provided. However, both read and unread TLDs needed to be zeroed and re-calibrated before subsequent use.

\section{Spare dosimeters}

In 2008, all HEU Transparency monitors went on assignments in Russia with a complete set of personal and control dosimeters. In order to avoid a failure of a trip mission due to lost dosimeters at customs, a pool of 24 spare dosimeters was maintained at TMC in Moscow, in addition to the 24 spare TLDs at the Pragma office. The number of spare dosimeters kept at TMC and Pragma was reduced from the 2007 quantities of 60 and 50 dosimeters respectively. This reduction of the spare dosimeters was based on the accumulated experience and the reduced number of monitors in a single team. The current number of spare dosimeters allows replacing the loss of all dosimeters of one single team. In such case the spare dosimeters will be replenished by the next team. In normal situations the spare dosimeters are exchanged semi-annually. In 2008 there was one case when the spare dosimeters from Moscow were used.

\section{Dose information from the Russian dosimeters}

The dose readings from the Russian TLDs (dosimeters) compare well within the statistical uncertainties with the readings from the U.S. dosimeters. The information from the Russian TLDs together with the arbitration TLDs (second U.S. dosimeter) is instrumental in resolving discrepancies and anomalies in the readings of the primary U.S. dosimeter. In 2008 we received the external dose readings from the Russian TLDs supplied to the U.S. monitors by the plants as follows: 
- SChE - for all SMVs and all monitors

- MPA - for all SMVs and all monitors

- ECP - for all SMVs and all monitors

- UEIE - none

\section{External dose investigations}

There have been 2 external dose investigations in 2008 which resulted in assigning an insignificant dose to one monitor. The monitor in question was on a back-to-back SMV (source change) and was inventorying daily a large number of containers for two weeks. The lesson learned is to alternate monitors for this task during the two-week SMVs. The second investigation resulted in zero dose assignment. For any dosimeter reading above $10 \mathrm{mrem}$, the arbitration TLD was analyzed together with the reported dose from the Russian TLD, when available, in order to evaluate if the monitor has/has not received an occupational dose from the HEU assignment in Russia. The arbitration and Russian TLDs, the radiological data we receive from the plants and personal interviews are used to resolve radiation exposure investigations.

No other external dose concerns were raised during the 2008 calendar year.

\section{Logistics and reporting}

Customs letters for both the U.S. and Russian customs were included in the dosimeters packages for each trip to facilitate customs inspections. LLNL retrieved all 2008 arbitration dosimeters from the monitored Russian nuclear facilities. In 2008 LLNL provided DOE's HEU Transparency Program management with post trip dose reports after each trip. All HEU monitors, except one, received zero doses from external radiation exposure in 2008. This single positive external dose was at the recording limit and well below the U.S. and the Russian regulatory limits for occupational and general public exposure.

\section{Internal dosimetry}

A total of 153 bioassay samples were submitted in 2008: 141 post-trip (for uranium) and 12 baseline samples ( 6 for uranium and 6 for plutonium). All HEU Transparency monitors who participated in assignments in Russian uranium processing facilities have provided baseline bioassay samples. All post trip bioassay samples from the 2008 calendar year were analyzed.

\section{Internal dose investigations}

One post trip bioassay sample showed results slightly above the investigation level. An additional follow-up bioassay sample was requested and analyzed extensively together with the original sample. The investigation concluded that no credible uranium uptake and internal dose can be attributed to this individual based on the HEU assignment.

There were no other internal dose concerns.

The internal dose is assigned based on the bioassay result (content of uranium compounds in urine), appropriate biokinetic models, chemical and physical form of 
uranium compounds, and other pertinent information. The minimum detectable internal dose (MDD) from uranium bioassays depends on several factors, two of which are the chemical and physical form of the uranium compound and the time elapsed between a potential uranium intake and the time the bioassay sample was provided. We can not control the first parameter, however we can try to shorten the time the bioassay sample is collected by obtaining it as close as possible to the day of the return to the USA. This allows lower uranium intakes and doses to be detected and will improve the reliability of the internal dose assessment.

\section{Bioassay sample compliance}

The established bioassay procedure requires each monitor to provide a post trip bioassay sample within 3 days of arrival in the USA. For 2008 calendar year, $90 \%$ of the samples were in compliance with this requirement, with the average time interval between the arrival of the monitors in the USA and the providing of the post trip bioassay sample being 1.7 days. Only 5 monitors have provided bioassay sample more than 10 days after their return to the U.S.A. Appendix A of this report has a chart providing information on the bioassay sample compliance for 2008 calendar year.

In 2008, LLNL provided the HEU Transparency Program management with quarterly internal dose reports (bioassay reports) containing information on the internal dose, the baseline bioassays, the procedure compliance and the status of bioassay samples received, analyzed and in process of being analyzed.

\section{HEU health physics information database}

LLNL maintains a confidential database for the HEU radiation protection data. The database contains historical external and internal dose information for every HEU Transparency monitor, as well as specific information for each trip, TLDs supplied, returned or left in Russia, baseline bioassays, submitted signed exposure release forms and monitor's data. The health physics database is essential for generating the post trip and the annual dose reports, as well as for any future inquiries. In order to comply with the provisions of the Privacy Act of 1984, we have obtained and keep on file signed Radiation Exposure Release forms for all HEU Transparency monitors that had assignments in the calendar year 2008.

The individual annual occupational dose information for each monitor for 2008, detailing the total dose as well as the external and internal doses from each monitoring assignment, was mailed to each monitor in January 2009.

\section{Radiological data from the Russian plants}

The 2008 radiological data, received from the Russian uranium processing plants under the HEU agreement, indicate that there are no radiological concerns for the U.S. monitors working in Russia who follow the work and personnel protection guidelines. The plant radiological data include gamma exposure rates, airborne and removable surface contamination levels in the areas visited by the U.S. monitors. These data supplement the information from the U.S. dosimeters and the bioassay sample analysis. 
The HEU Purchase Agreement documents have provisions for all plants that the radiological environment data be provided to the US for the areas visited by the U.S. monitors. However, they do not specify what data, in what format, for what time intervals, or any other details to be provided to the U.S. For example a provision for sharing contamination or radiological accident data affecting the US monitors is not specified in the HEU Purchase Agreement documents.

In 2008 we received the following radiological data from the plants:

- ECP - gamma exposure rates, surface alpha contamination, and airborne alpha contamination for each day of the SMV and for all SMVs;

- MPA -gamma exposure rates, surface alpha contamination, and airborne alpha contamination for each day of the SMV and for all SMVs;

- SChE-gamma exposure rates, surface alpha contamination, and airborne alpha contamination averaged for the 5 days of each SMV (we do not yet have 08-6 data);

- UEIE -gamma exposure rates, surface alpha contamination, airborne alpha contamination, and neutron dose rates at the BDMS room averaged over a one-month period with June-July averaged together (we do not have data for September and December since no U.S. monitors were present at UEIE).

The graphs in Appendix B (Appendix B is a separate C/FGI-MOD document) provide the gamma exposure levels and the airborne and surface contamination at the monitoring points and guiding action levels for each of the plants in 2008. A short discussion of the 2008 radiological data from the plants is included in Appendix B.

Detailed plant radiological data along with the action levels and the recommended precautions are included in each trip's Team Instructions Book.

\section{Health physics support of the BDMS activities}

During CY 2008 LLNL provided health physics support during the BDMS sources replacement at SChE, ECP and UEIE. LLNL provided support for the dose rate measurements around the Blend Down Monitoring Systems (BDMSs) for Russian regulatory compliance and support for neutron dosimetry to SChE, UEIE, the Russian Federal Nuclear Center - Institute of Technical Physics (VNIITF, C-70), and ECP.

Neutron and gamma dose rate measurements for regulatory compliance and radiation safety reports for the BDMS source replacement

A consistent dose rate measurement methodology for regulatory compliance is used in all Russian plants. This methodology improves the accuracy and allows a better comparison of measurement results from different years and different sources. The quality and the accuracy of the measurement results provide additional confidence in the source characteristics and their proper installation and manipulation. During the SChE, ECP and UEIE source replacement visits, detailed gamma and neutron dose rate measurements were performed at the surface and at one meter from all BDMS units with the assistance and in the presence of a U.S. health physicist. The measurement results were included in the radiation safety reports for the BDMS sources replacements. The radiation safety 
reports indicate that during and after source replacement the individual doses, as well as the gamma and neutron dose rates around the BDMS, did not exceed the Russian radiation safety limits. All plants applied less stringent regulatory limits that are based on the lower occupancy levels (less than $8 \mathrm{hr}$ /day and $40 \mathrm{hr} /$ week) in the BDMS premises. These less stringent limits allow six times higher radiation dose rates at 1 meter from the BDMS units and allow the use of stronger sources that can increase the time between source changes resulting in substantial savings to the HEU Transparency Program. These regulatory limits are reflected in the BDMS radiation safety reports for the past several years.

The UEIE document does not mention any radiation safety report or dose rate measurements during the BDMS source replacement. ECP and SChE HEU Purchase Agreement documents were negotiated after the difficulties experienced with obtaining a detailed radiation safety report from UEIE. Both ECP and SChE HEU Purchase Agreement documents state that upon U.S. request the plant shall provide "....the results of dosimetric confirmation measurements at the HEU-LEU blending area during the replacement of radioactive sources." In 2008 we received the following BDMS radiation safety reports:

- $\mathrm{SChE}$ - the report includes the data from each gamma and neutron dose rate measurement. It was signed by the Head of Radiation Monitoring Group at the Enrichment Plant and a U.S. health physicist. The report was provided to the U.S. during the next SMV following plant's security review.

- $\quad$ ECP - the report includes the data from each dose rate measurement and was signed by the ECP Head of Radiation Safety Service and the U.S. HEU health physicist. Air monitoring data for alpha and beta contamination, as well as for surface contamination at the blend point facility during the visit were below the Russian and the U.S. regulatory limits. These data were included in the report. We obtained the signed radiation safety report at the end of the source change visit.

- UEIE - the report includes the detailed dose rate measurement data and is signed by the UEIE radiation safety. Measurements of the airborne alpha particles concentration, as well as, surface alpha contamination in the blend point facility during the visit were below the Russian and the U.S. regulatory limits. These data were included also in the report. The report was provided to the U.S. during the next SMV following plant's security review.

The BDMS radiation safety reports document that during and after source replacement the individual doses to all Russian and U.S. personnel involved, as well as the gamma and neutron dose rates around the BDMS, did not exceed the Russian radiation safety limits and that all source replacement operations were conducted adhering to the ALARA (As Low As Reasonably Achievable) principle.

\section{BDMS sources specifications}

HEU health physicist provided assistance in developing the source specifications and ordering stronger sources which will allow longer intervals between source change campaigns. The specifications were developed in a manner to maximize the output and the reliability of the BDMS measurements and, at the same time, to comply with the 
Russian Federation radiation safety regulatory limits. The specifics of the dose rate measurement instrumentation and treatment of measurement errors were taken into account in the development of the source specifications.

\section{Bubble dosimeters}

During CY 2008 LLNL shipped 80 bubble dosimeters with high sensitivity ( 20-30 bubbles per mrem) to SChE, ECP and UEIE to support the BDMS sources changes. The bubble dosimeters are used to measure the individual neutron doses for the personnel from the involved plant, VNIITF and the U.S. monitors. The bubble dosimeter information is valuable for the U.S. monitors and the Russian personnel as an immediate indication in case of a significant neutron exposure or radiation leakage from the BDMS shielding. The current status of the mutually-agreed-to number of bubble dosimeters for the source replacement visits is shown in Table 1.

Table 1 - Current status of the number of bubble dosimeters

\begin{tabular}{|l|c|c|}
\hline & Cf-252 source change & Co-57 only source change \\
\hline UEIE & 15 & 10 \\
\hline ECP & 15 & 10 \\
\hline SChE & $40^{\star}$ & - \\
\hline
\end{tabular}

* LLNL is expecting that SChE radiation safety will agree with a lower number (15) of bubble dosimeters per source change consistent with the other plants based on the good radiation safety practice and the radiation safety measures and controls during source replacement and relative $\mathrm{Cf}$ sources measurements.

\section{Information on HEU electronic information system (EIS)}

The available data on EIS in the BDMS directory include two folders - BDMS Sources and Bubble Dosimeters for the use of the HEU community.

The BDMS Sources folder contains:

- All current and past Cf-252, Co-57 and Am-241 passports for UEIE, ECP and SChE BDMS sources

- Co-57, Am-241, and Cf-252 source specifications

- All radiation safety reports for the source change activities in English and the Russian originals for UEIE, ECP and SChE

- Tables of the detailed dose rate (gamma+neutron) measurements at UEIE, ECP and $\mathrm{SChE}$ for regulatory compliance

- Tables of the relative californium source measurements of the new, old, and the reference sources with any pertinent information for source changes and installations at the three plants

- Tables of the Cf-252, Co-57, and Am-241 source positions at UEIE, ECP, and SChE 
The bubble dosimeter folder on EIS contains:

- Test results from the 2002 and 2008 certification of the bubble dosimeters by Doza (in Russian)

- 2003 and 2008 Bubble Dosimeter Accreditation certificate - original in Russian and the English translation

- Accreditation testing report and description - in Russian and in English

\section{Reporting}

In 2008 LLNL provided the following reports related to the health physics issues of the HEU Transparency Program activities:

- Post trip dose reports after each trip

- Quarterly bioassay (internal dosimetry) reports

- 2007 Annual Health Physics Report for the HEU Transparency Program

- 2007 Annual Occupational Dose Reports to each monitor that had a trip to Russia

- 2007 Annual Occupational Dose Reports to the POC for all monitors in his area

- U.S.-Russian radiation safety reports for regulatory compliance after the UEIE and ECP BDMS source replacement.

- Reports on various health physics topics requested by the HEU Transparency Program management

\section{Conclusion}

In 2008, the HEU Transparency activities in Russia were conducted in a radiologically safe manner for the HEU Transparency monitors in accordance with the expectations of the HEU Transparency staff, NNSA and DOE. The HEU Transparency now has thirteen years of successful experience in developing and providing health and safety support in meeting its technical objectives. 
Appendix A - 2008 Bioassay sample compliance

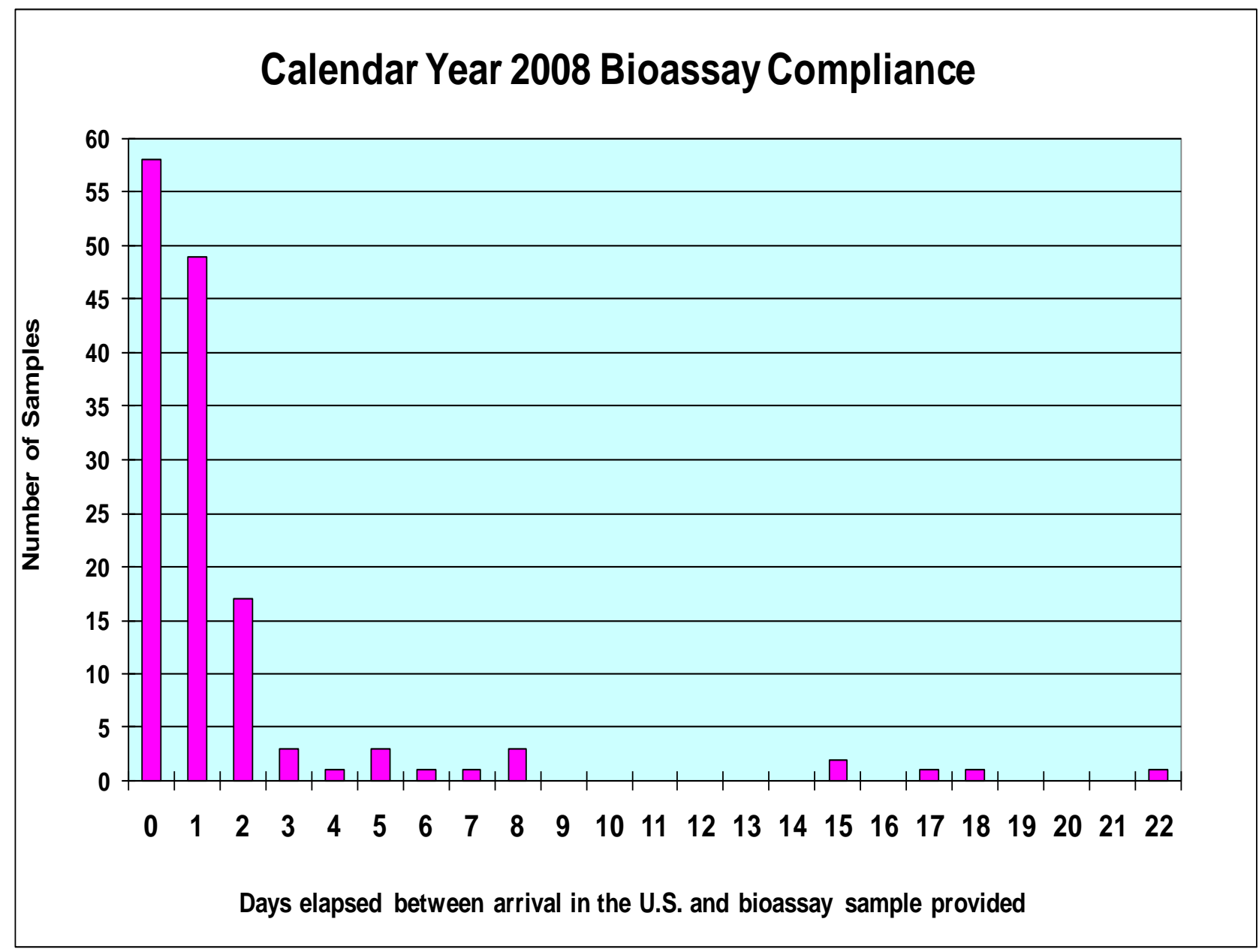


Appendix B - 2008 Russian plants radiological data charts

Appendix B is a separate document that is marked C/FGI-MOD 